\title{
ANÁLISE DAS PROPRIEDADES DO CONCRETO COM SUBSTITUIÇÃO PARCIAL DO CIMENTO E DO AGREGADO MIÚDO POR VIDRO MOÍDO
}

\author{
FONSECA, VITOR HYGOR N. \\ ENGENHEIRO CIVIL \\ UNIVASF \\ BAHIA; BRASIL \\ VICTOR_HYGOR@HOTMAIL.COM
}

\author{
BARBOSA, ANDERSON H. \\ PROFESSOR \\ UNIVASF \\ BAHIA; BRASIL \\ ANDERHB80@GMAIL.COM
}

\author{
GRANJA, JAILMA M. M. \\ GRADUANDA EM ENGENHARIA CIVIL \\ UNIVASF \\ BAHIA; BRASIL \\ JAILMA_GRANJA_@HOTMAIL.COM
}

\section{RESUMO}

O vidro é amplamente utilizado na nossa sociedade, além de ser um material boas características de reciclagem. Neste trabalho é estudada a avaliação da incorporação do resíduo de vidro moído como substituto parcial do cimento e do agregado miúdo nas propriedades mecânicas do concreto. O resíduo utilizado para desenvolver este estudo foi recolhido em vidraçarias da cidade de Petrolina - PE, passando por posterior moagem e separação em duas granulometrias, uma para substituição do cimento e outra para o agregado miúdo. Foram confeccionados corpos de prova de concreto com a substituição nas proporções de $5 \%, 10 \%, 15 \%$ e $20 \%$ de cimento e $25 \%$ e $50 \%$ de agregado miúdo por vidro moído para determinar a resistência à compressão (7, 21 e 28 dias), teste de abatimento e absorção de água. Os resultados dos ensaios foram comparados com a amostra base sem adição de vidro, mostrando ganho de resistência à compressão quando adicionado vidro substituindo o cimento na proporção de 5\%, chegando a um acréscimo de 15,24\%, nos teores de subsituição maiores provocou redução da ordem de $11 \%$ a $28 \%$. Quando substituindo o agregado, reduziu em 6,38\% e $8,16 \%$ para as proporções de $25 \%$ e $50 \%$, respectivamente. Nas propriedades de absorção de água, massa especifica e índice de vazios não há alteração significativa com essas substituições, demostrando que em pequenas proporções o vidro moído é uma boa alternativa para substituir os materiais que compõem o concreto.

Palavras-chave: Vidro. Concreto. Reciclagem. Aglomerante. Agregado.

\begin{abstract}
Glass is widely used in our society, and is a material with good recycling characteristics. In this work, the evaluation of the incorporation of ground glass waste as a partial substitute of cement and fine aggregate in the mechanical properties of concrete is studied. The waste used to develop this study was collected in glassmakers, undergoing subsequent grinding and separation into two granulometries, one for cement replacement and the other for fine aggregate. Concrete specimens were made with the replacement in the proportions of 5\%,10\%, $15 \%$ and $20 \%$ of cement and $25 \%$ and $50 \%$ of fine aggregate by ground glass to determine the compressive strength, slump test and water absorption. The results were compared with the base sample without glass, showing compressive strength gain when added glass replacing the cement in the proportion of 5\%, reaching an increase of $15.24 \%$, presenting a reduction of $11 \%$ to $28 \%$ for the other substitutions. When replacing the aggregate, it decreased by $6.38 \%$ and $8.16 \%$ to the $25 \%$ and $50 \%$ proportions, respectively. In the water absorption, specific mass and void properties there is no significant change with these substitutions.
\end{abstract}

Keywords: Glass. Concrete. Recycling. Binder. Aggregate. 


\section{INTRODUÇÃO}

O vidro é uma substância sólida e amorfa, que tem uma utilização generalizada na nossa sociedade, podendo ser aplicado em embalagens comuns de alimentos ou até na construção civil, como esquadrias ou elementos de vedação vertical, entre outros.

Segundo dados do Compromisso Empresarial para Reciclagem - CEMPRE (2013), o Brasil produz em média 980 mil toneladas de embalagens de vidro por ano, e mesmo sendo um material que possui um reaproveitamento de $100 \%$, cerca de 470 mil ton/ano são recicladas. A reciclagem total desse material poderia poupar milhares de reais, além do custo ambiental do descarte inadequado na natureza, já que estudos sugerem que a decomposição natural do vidro demora mais de 4 mil anos.

O desenvolvimento tecnológico na construção civil contribui cada vez mais para suprir as demandas técnicas e ambientais exigidas atualmente. Novos materiais são estudados para ampliar as opções na construção civil. O reaproveitamento e a reciclagem têm um papel gigantesco neste ponto, já que por se tratar de uma indústria que demanda uma grande quantidade de matéria-prima não renovável.

O concreto é um material amplamente utilizado na construção civil, pois é um material mais versátil comparando a outros materiais utilizados na construção civil, como o aço. A utilização do concreto tem como principais vantagens como resistência à água, a fácil moldagem e o baixo custo. Convencionalmente, é constituído por um material ligante, o cimento, agregados graúdos, agregados miúdos e água.

Contribuindo para alternativas mais eficientes para destinação destes materiais, a construção civil pode reaproveitar os resíduos de vidro na composição de novos materiais com desempenho técnico e vantagens econômicas.

Várias pesquisas já foram feitas sobre o aproveitamento de vidro moído em traços de argamassa e concreto, segundo Crentsil (2011 apud TRAVAIN, AZAMBUJA E JAVARONI, 2014, p.2), o uso de vidro no concreto é estudado e aplicado em vários lugares do mundo. Em países como Austrália, o vidro moído proveniente do lixo é usado em concretos para construção, em Nova York foram criadas recomendações para o uso deste material em concretos.

Sendo assim, neste trabalho propõe-se o estudo das propriedades mecânicas do concreto com a incorporação do resíduo de vidro moído, substituindo parcialmente o cimento e o agregado miúdo, ajudando a verificar possíveis futuras aplicações deste material na construção civil.

\section{RECICLAGEM DO VIDRO}

De acordo com Santos (2003 apud TRAVAIN, AZAMBUJA E JAVARONI, 2014), o vidro é uma substância inorgânica, amorfa e fisicamente homogênea. Pode ser obtido por resfriamento de uma massa em fusão que endurece pelo aumento contínuo de viscosidade até atingir a condição de rigidez, sem sofrer cristalização.

O vidro distingue-se de outros materiais por várias características: não é poroso nem absorvente, é ótimo isolador, possui baixo índice de dilatação e condutividade térmica, suporta pressões de 5.800 a $10.800 \mathrm{~kg} / \mathrm{cm}$.

(RODOVIDRO, 2011). O vidro é um material frágil, porém não fraco. Ele tem grande resistência à ruptura, podendo mesmo ser utilizado em pisos, é duro e rígido, porém não tenaz, não sendo apropriado para aplicações sujeitas a impactos (OLIVEIRA et al., 2012).

De acordo com Petrucci (1976), a composição ponderável de vidros ordinários é de 71,5\% de SiO2 (sílica), 15\% de $\mathrm{Na} 2 \mathrm{O}$ (óxido de sódio) e 15,5\% de $\mathrm{CaO}$ (óxido de cálcio).

Devido ao baixo preço por quilo do vidro na reciclagem, ele se torna um material desvalorizado, para encontrar um meio vantajoso de remover esse resido do meio ambiente, vários estudos tentam verificar futura aplicações desse material ou de seu processo de produção dentro da construção civil.

Segundo Soroushian (2012 apud MARTÍNEZ et al., 2015), o vidro moído entra em uma reação benéfica com os hidratos do cimento. Aproximadamente $20 \%$ do cimento utilizado para produzir o concreto pode ser substituído por vidro moído (reciclado), gerando uma economia significativa no cimento. 
Shao et al. (2000 apud RIGHI et al., 2012), pesquisaram a possibilidade de incorporação de partículas de vidro finamente moídas, como substituição parcial do cimento, na produção de concretos. Nesse ensaio foi substituído $30 \%$ do volume de cimento por vidro moído com tamanhos de partículas de vidro moído menores do que $75 \mu \mathrm{m}$, comprovando que os tamanhos de partículas do vidro moído demostraram efeito no desempenho do concreto, aumentando sua resistência à compressão, também uma menor expansão quando comparado com o traço padrão.

Estudos de Lopez (2003 apud RIGHI et al., 2012), mostram uma tendência de aumento da tensão média de ruptura com o aumento da granulometria do material até atingir a granulometria entre 0,15-0,30 mm, após o qual a tensão de ruptura diminui novamente se mantendo num patamar, porém, superior ao do corpo de prova de referência. Este aumento da tensão média poderia ser causado pelo preenchimento de vazios pelo vidro fino. Os espaços entre os agregados utilizados, principalmente entre a areia, estariam sendo ocupados pelo vidro, fazendo com que o material fique mais resistente.

estudo de Oliveira et al. (2012), a substituição parcial do cimento por vidro moído apresentou resultados abaixo da referência, mas os corpos de prova com substituição de 5\% e 10\% apresentaram resultados satisfatórios, tanto para resistência à compressão axial como para o módulo de elasticidade.

Nos ensaios apresentados por Santos, Santos e Seydell (2015), houve um pequeno ganho na resistência a compressão do concreto para as amostras de $10 \%$ e $15 \%$, porém, ocorreu uma queda de resistência à compressão nos corpos de prova com $20 \%$ de adição de pó de vidro.

Segundo os dados de Fernandes e Lintz (2006), o a substituição do cimento Portland por pó de vidro na proporção de $10 \%$ causa um ganho na resistência à compressão, tração e flexão no concreto. Na proporção de $15 \%$, houve uma redução da resistência a flexão, porém, deve salientar-se o ganho considerável no ensaio de resistência a tração.

Polley e Cramer (1998 apud TRAVAIN, AZAMBUJA e JAVARONI, 2014) pesquisaram o uso de vidro reciclado como substituto do agregado fino no concreto. Os resultados dessa pesquisa indicaram que o vidro é um substituto satisfatório para agregados naturais finos em níveis de até $20 \%$ do agregado total com resistências à compressão compatíveis com concretos do mesmo traço sem adição de vidro.

\section{PROCEDIMENTO EXPERIMENTAL}

Foram utilizados para a produção dos concretos os seguintes materiais:

- $\quad$ cimento Portland composto CP II-Z-32

- Agregado graúdo de pedra britada $25 \mathrm{~mm}$.

- Agregado miúdo de areia lavada de rio.

O resíduo de vidro usado para desenvolver o estudo foi coletado em vidraçarias da região, contendo vários tipos de vidro, como: vidros temperados, vidros laminados, espelhos e garrafas de vidro. A Figura 1 apresenta um exemplo das características dos resíduos de vidro.

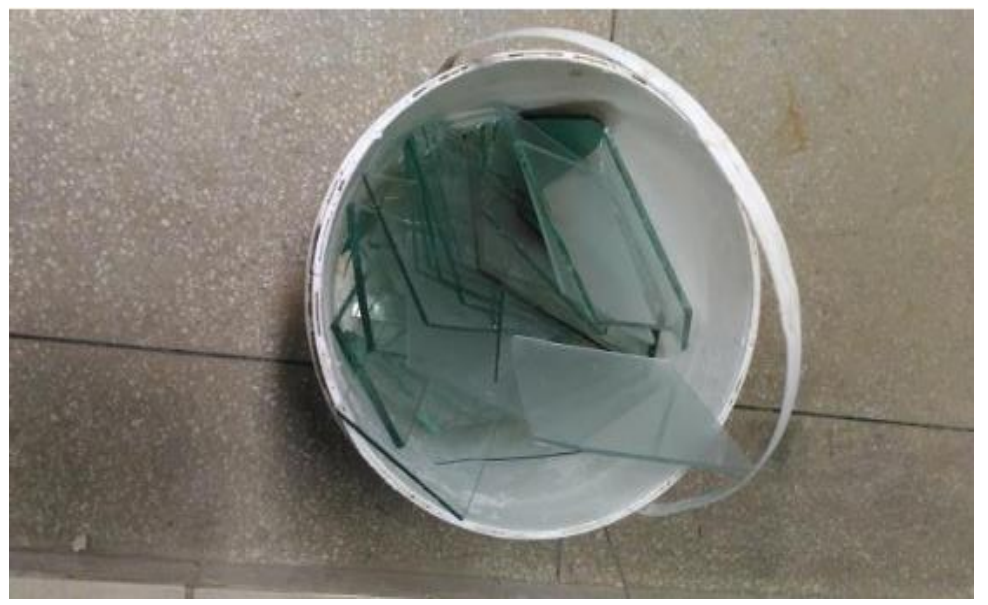

Figura 1: Aspecto do resíduo de vidro coletado. 
Para moer o material, o resíduo de vidro foi despejado em um moinho de bolas de laboratório cilíndrico movido a motor, junto com 12 esferas de ferro. O moinho ficou ligado por aproximadamente 10 horas, sendo retirado após atingir o tamanho desejado. Como exemplo, tem-se a Figura 2.

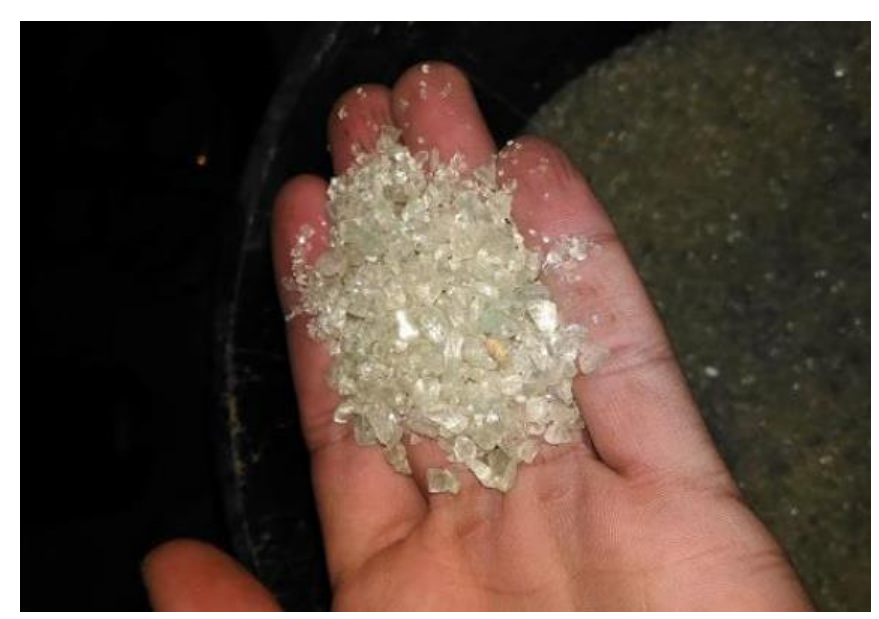

Figura 2: Aspecto do resíduo de vidro moído.

Em seguida houve o primeiro peneiramento, utilizando uma peneira de $4,75 \mathrm{~mm}$, para separar o resíduo graduo do miúdo. O material retido, aproximadamente $1 / 4$ do volume total de vidro inicialmente recolhido, foi descartado e o passante foi levado para um segundo peneiramento. O segundo peneiramento foi utilizando a peneira de $150 \mu \mathrm{m}$, na qual, o que ficou retido foi usado para substituir o agregado miúdo no concreto e o que passou foi usado para substituir o cimento no concreto.

Como resultado da caracterização dos materiais utilizados, observe a Tabela 1:

Tabela 1 - Valores dos ensaios de massa específica e absorção de água.

\begin{tabular}{c|l}
\hline Vidro & Massa específica: $2,558 \mathrm{~g} / \mathrm{cm}^{3}$ \\
\hline Cimento & Massa específica: $2,941 \mathrm{~g} / \mathrm{cm}^{3}$ \\
\hline \multirow{3}{*}{ Agregado miúdo } & $\begin{array}{l}\text { Massa específica: } 2,632 \mathrm{~g} / \mathrm{cm}^{3} \\
\text { Diâmetro máximo: } 1.18 \mathrm{~mm} \\
\text { Módulo de finura: } 1,60\end{array}$ \\
\hline \multirow{2}{*}{ Agregado graúdo } & $\begin{array}{l}\text { Massa específica: } 2,61 \mathrm{~g} / \mathrm{cm}^{3} \\
\text { Diâmetro máximo: } 19 \mathrm{~mm}\end{array}$ \\
\hline
\end{tabular}

O estudo em questão tem como objetivo a análise do concreto nos seguintes casos:

- Concreto sem a substituição do cimento Portland e do agregado miúdo por vidro;

- Concreto com 5\%, 10\%, $15 \%$ e $20 \%$ de vidro moído substituindo proporcionalmente o cimento Portland;

- Concreto com $25 \%$ e $50 \%$ de vidro moído substituindo proporcionalmente o agregado miúdo.

O traço unitário utilizado foi 1:1,31:2,47:0,471 (cimento : areia : brita : água). 
Foram moldados 12 corpos de prova de cada proporção de acordo com a NBR 5738/2015, 3 para o ensaio de resistência à compressão em 7 dias, 3 para o ensaio de resistência à compressão em 21 dias, 3 para o ensaio de resistência à compressão em 28 dias e 3 para o teste de absorção de água. Os corpos de prova foram confeccionados em moldes metálicos cilíndricos com $10 \mathrm{~cm}$ de diâmetro e $20 \mathrm{~cm}$ de altura. O método de adensamento foi o de vibração, realizado com um vibrador de imersão no concreto.

Além do ensaio de resistência à compressão, foram avaliadas a massa específica dos concretos e sua respectiva absorção de água.

\section{RESULTADOS E DISCUSSÕES}

Os resultados dos ensaios de resistência à compressão para cada corpo de prova são apresentados na Tabela 2.

Tabela 2 - Valores individuais e médios para os concretos produzidos.

\begin{tabular}{|c|c|c|c|c|c|c|}
\hline \multirow{3}{*}{ Traço } & \multicolumn{6}{|c|}{ Idade } \\
\hline & \multicolumn{2}{|c|}{7 dias } & \multicolumn{2}{|c|}{21 dias } & \multicolumn{2}{|c|}{28 dias } \\
\hline & Individual & Média & Individual & Média & Individual & Média \\
\hline \multirow{3}{*}{ Referência } & 26,88 & \multirow{3}{*}{21,56} & 31,90 & \multirow{3}{*}{28,67} & 28,72 & \multirow{3}{*}{31,61} \\
\hline & 18,78 & & 27,27 & & 34,78 & \\
\hline & 19,01 & & 26,85 & & 31,32 & \\
\hline \multirow{3}{*}{$5 \%$ cimento } & 25,07 & \multirow{3}{*}{24,82} & 31,31 & \multirow{3}{*}{32,53} & 35,64 & \multirow{3}{*}{36,23} \\
\hline & 23,67 & & 33,46 & & 36,95 & \\
\hline & 25,72 & & 32,81 & & 36,09 & \\
\hline \multirow{3}{*}{$10 \%$ cimento } & 21,41 & \multirow{3}{*}{20,76} & 25,44 & \multirow{3}{*}{27,68} & 26,98 & \multirow{3}{*}{28,09} \\
\hline & 18,84 & & 27,04 & & 26,93 & \\
\hline & 22,04 & & 30,55 & & 30,36 & \\
\hline \multirow{3}{*}{$15 \%$ cimento } & 17,76 & \multirow{3}{*}{18,87} & 24,81 & \multirow{3}{*}{21,83} & 28,05 & \multirow{3}{*}{25,69} \\
\hline & 19,62 & & 20,42 & & 26,12 & \\
\hline & 19,24 & & 20,25 & & 22,89 & \\
\hline \multirow{3}{*}{$20 \%$ cimento } & 17,00 & \multirow{3}{*}{15,80} & 17,67 & \multirow{3}{*}{21,15} & 24,02 & \multirow{3}{*}{22,61} \\
\hline & 15,40 & & 21,15 & & 21,87 & \\
\hline & 15,01 & & 24,62 & & 21,95 & \\
\hline \multirow{3}{*}{$25 \%$ agregado } & 23,56 & \multirow{3}{*}{23,23} & 24,82 & \multirow{3}{*}{24,00} & 29,32 & \multirow{3}{*}{29,52} \\
\hline & 21,86 & & 23,69 & & 29,28 & \\
\hline & 24,27 & & 23,50 & & 29,96 & \\
\hline \multirow{3}{*}{$50 \%$ agregado } & 23,46 & \multirow{3}{*}{23,17} & 27,92 & \multirow{3}{*}{27,93} & 31,36 & \multirow{3}{*}{29,61} \\
\hline & 22,97 & & 30,84 & & 28,76 & \\
\hline & 23,07 & & 25,04 & & 28,70 & \\
\hline
\end{tabular}

Analisando os dados da Tabela 2, percebe-se um aumento da resistência à compressão média do concreto quando substituído o cimento por vidro na proporção de 5\%, chegando a um acréscimo de $15 \%$ na sua resistência. Também é observado uma diminuição da resistência à compressão a partir da proporção de $10 \%$ de vidro moído substituindo o cimento, chegando a uma diferença de $30 \%$ de resistência à compressão na proporção de $20 \%$ de vidro substituindo o cimento, como esperado, já que o vidro tem características aglomerantes menor que o cimento.

Nas proporções onde é substituído o agregado miúdo por vidro moído, houve uma diminuição na resistência à compressão de $6,38 \%$ para a proporção de $25 \%$ e de $8,16 \%$ para a proporção de $50 \%$. Considerado uma pequena diminuição de resistência, mesmo com o módulo de finura do vidro moído sendo maior que do agregado miúdo. Uma explicação para isso seria que o vidro possui uma resistência mecânica maior que do agregado, compensando a resistência perdida pelo aumento dos grãos.

Os resultados da determinação da massa específica do concreto estão apresentados na Tabela 3. Além disso, são indicados os dados de absorção de água e índice de vazios. 
Tabela 3 - Valores dos ensaios de massa específica e absorção de água.

\begin{tabular}{c|c|c|c|c}
\hline Traço & $\begin{array}{c}\text { Absorção de água } \\
\text { por imersão }(\%)\end{array}$ & Índice de vazios $(\%)$ & $\begin{array}{c}\text { Massa específica da } \\
\text { amostra seca }\left(\mathrm{g} / \mathrm{cm}^{3}\right)\end{array}$ & $\begin{array}{c}\text { Massa específica da } \\
\text { amostra saturada }\left(\mathrm{g} / \mathrm{cm}^{3}\right)\end{array}$ \\
\hline Referência & 5,41 & 12,36 & 2,284 & 2,408 \\
\hline $5 \%$ cimento & 5,46 & 12,35 & 2,262 & 2,385 \\
\hline $10 \%$ cimento & 5,24 & 11,98 & 2,286 & 2,406 \\
\hline $15 \%$ cimento & 5,55 & 12,79 & 2,305 & 2,433 \\
\hline $20 \%$ cimento & 6,07 & 13,66 & 2,252 & 2,388 \\
\hline $25 \%$ agregado & 5,41 & 12,38 & 2,286 & 2,410 \\
\hline $50 \%$ agregado & 5,03 & 11,59 & 2,302 & 2,417 \\
\hline
\end{tabular}

Analisando a Tabela 3 foi esperado uma diminuição da absorção de água com o aumento da proporção de vidro moído, que de fato aconteceu nas amostras com substituição do agregado miúdo, porém, nas amostras com substituição de cimento por vidro moído houve um leve aumento de absorção de água e índice de vazios.

Também se observa que a massa específica da amostra seca e a massa específica da amostra saturada das amostras não houveram variações significativas nos resultados, uma vez que, para criação do traço do concreto foi levado em consideração a massa especifica dos materiais.

\section{CONCLUSÃO}

Com os resultados deste estudo foi concluído que:

- Assim como os estudos de Santos, Santos e Seydell (2015) e de Fernandes e Lintz (2006), este estudo houve um aumento da resistência à compressão com a substituição do cimento por agregado miúdo em pequenas proporções. A diferença é que, o pico de resistência à compressão deste estudo ficou em torno da proporção de $5 \%$, ganhando aproximadamente $15 \%$ de resistência à compressão comparando com o concreto base, já o estudo de Santos, Santos e Seydell (2015) tem pico de resistência à compressão em torno da proporção de $15 \%$, ganhando $7,6 \%$ de resistência, e o estudo de Fernandes e Lintz (2006) o pico fica em torno da proporção de $10 \%$, com um ganho de $29,3 \%$ de resistência. Isso demostra a viabilidade do concreto quando substituído o cimento por vidro moído em pequenas proporções, sendo uma boa alternativa para o descarte do vidro e a diminuição do consumo de cimento;

- Também deve ser salientado que neste estudo o concreto nas proporções de $10 \%$ e $15 \%$ de cimento substituído por vidro moído houve uma pequena diminuição da resistência à compressão, porém ficando muito próximo da resistência a compressão do concreto base, sendo também uma boa alternativa do uso do vidro no concreto.

- Confirmando o estudo de Polley e Cramer (1998), que mostrou a diminuição da resistência à compressão do concreto quando substituído o agregado miúdo por vidro moído, este estudo também demostrou uma diminuição da resistência a compressão do concreto comparado ao concreto base.

- Assim como os estudos de Travain, Azambuja e Javaroni (2014) e de Martínez et al. (2015), neste estudo não houve alterações significativas nos resultados para absorção de água. Isso demostra que a substituição de cimento e agregado miúdo por vidro moído não interfere na absorção de água do concreto.

- Há um consumo menor de água na produção do concreto quando substituído o cimento ou o agregado miúdo por vidro moído. Quanto mais aumentar a proporção da substituição, menor será a necessidade de água para produzir o concreto.

\section{REFERÊNCIAS}

ASSOCIAÇÃO BRASILEIRA DE NORMAS TÉCNICAS. NBR 5738: Concreto - Procedimento para Moldagem e cura de Corpos de prova cilíndricos ou prismáticos de concreto. Rio de Janeiro: ABNT, 2015.

FERNANDES, P. C.; LINTZ, R. C. C., Estudo do reaproveitamento do pó de vidro em materiais compósitos. $58^{a}$ Reunião Anual da SBPC, 2006. Florianópolis/SC.

OLIVEIRA, M. C. R.; SILVA, A. L. B.; PEREIRA, F. F. A.; COSTA, G. L. S.; M., S. Concreto especial produzido a partir da substituição parcial do cimento portland por resíduos de vidro. Congresso Brasileiro de Concreto, 8 , 2012. Anais. Maceió/AL. 
PETRUCCI, E. G. R. Materiais de Construção. $2^{a}$ ed. Porto Alegre: Editora Globo, 1976.

RIGHI, D.; KÖHLER, L.; TABARELLI, A.; KIRCHHOF, L.; LIMA, R. Análise de concretos produzidos com vidro moído quando submetidos à elevadas temperaturas. XXXV Jornadas sul americanas de engenharia estrutural, 16, Rio de Janeiro/RJ, 2012.

RODOVIDRO. O vidro. Disponível em: <http://www.rodovidro.com.br/ovidro.html>. Acesso em: 18 abr. 2017.

SANTOS, M. I. S.; SANTOS, F. N.; SEYDELL, M. R. R. Avaliação do comportamento mecânico de concreto estrutural com adição de resíduos de pó de vidro em substituição parcial do cimento. Congresso Brasileiro de Concreto, 16, 2015. Anais. Bonito/MS.

TRAVAIN, M. D.; AZAMBUJA, M. A.; JAVARONI, C. E., Estudo da substituição parcial de areia por vidro moído em concreto. Congresso Brasileiro de Concreto, 13, 2014. Anais. Natal/RN. 